\title{
A proposal for an ergonomic redesign for a mixer Mondial B-02
}

\author{
Silva Junior, Adilson J. ${ }^{\mathrm{a},{ }^{*}}$ and Barros, Bruno ${ }^{\mathrm{b}}$ \\ ${ }^{a}$ Universidade Federal de Pernambuco- Núcleo de Design. Rodovia BR 104. KM 60, Sítio Juriti - Caruaru - PE \\ - Brasil - CEP: 55002-970. \\ ${ }^{\mathrm{b}}$ Universidade Federal de Pernambuco- Núcleo de Design. Rodovia BR 104. KM 60, Sítio Juriti - Caruaru - PE \\ - Brasil - CEP: 55002-970.
}

\begin{abstract}
This research aimed to redesign an appliance based on the biomechanical aspects in applied ergonomics. The product chosen for analysis was the household mixer, it is readily found in most homes of several families. The study enabled the identification of several potential risks and proposed biomechanical ergonomic solutions for each. Finally, it was possible to redesign the handle of the mixer, making it suitable form and human use.
\end{abstract}

Keywords: Product ergonomics, Biomechanical Risk, Domestic Appliances, Mixer.

\section{Introduction}

Our everyday life is full of interactions with products of all kinds, we have furniture, electronics, appliances sociological and others. Often unaware of the inadequacies which we must subject all day, but examples of these inadequacies are even in the smallest product.

The study is the result of a research project conducted at the Federal University of Pernambuco, where the main objective was to propose the redesign of an appliance of a lot of interface with hands. As an object of study was selected Mixer B-02 brand Mondial.

The Mixer is a household appliance, used to beat mechanically ingredients or mixtures of cooking recipes. The electric models are formed by a small motor that rotates one or two pieces shaped whisk.

For the redesign of the product we present a survey of anthropometric and biomechanical data about the problems encountered and design solutions to be applied.

By identifying structural components that do not allow the comfortable use of the product, the proposal aims to add the product relevant factors that have the possibility of proper handling and consistent with the principles of ergonomics.

\section{Literature Review}

The contents of all the research was guided by the definition of Ergonomics (or Human Factors) ed-ed in August 2000 by SIA - the Inter-national ergonomics.

Ergonomics is a scientific discipline related to nothing the understanding of the interactions between humans and other elements or systems, and apply-ing theories, principles, data and projection methods-ments in order to optimize human well-being and performance overall system. Ergonomists contribute to the planning, design and evaluation of tasks, jobs, products, environments and systems to make them compatible with the needs, abilities and limitations of people.

Ideally, ergonomics must be applied from the initial design stages [...]. These should always include the human being as one of its components. [...] User characteristics must be considered together

*Corresponding author: SILVA JUNIOR, Adilson J. E-mail: adilson574@hotmail.com

1051-9815/12/\$27.50 C 2012 - IOS Press and the authors. All rights reserved 
with the characteristics of mechanical parts or restrictions or environmental, to fit each other mutually. (IIDA, 2005) [3].

According to Iida (2005) [3], when it comes to designing products for humans, the most important requirement, about which one should not make concessions, is the security of the user because there is nothing that redeems the suffering, mutilations and sacrifices caused to humans. Therefore it is of paramount importance in the action projectual consider, first, the factors.

Projects can be developed for population groups, seeking cover from 5 to $95 \%$ of it. In the industrial environment, there are few projects developed especially for an individual. This type of product provides better fit between product and user, but greatly increases the cost (PANERO AND ZELNICK, 2008) [7], so it is more correct design for the extremes.

We redesign the product following the concepts of biomechanics (the area of ergonomics studies the "human machine"), specifically the Occupational Bio-mechanics is the study of the physical relationship of the worker with tools, machines and materials, aiming to improve their performance, while minimizing the risk of involvement of musculoskeletal injuries (CHAFFIN, ANDERSSON \& MARTIN, 2001) [1].

Based on assumptions of Anthropometry discipline based on physical anthropology, which studies the shape and dimensions of the segments of the human body - use some anthropometric data to support the changes made in the product. There are numerous anthropometric data that can be used [...] in the design of products in general (SANTOS, 1998) [6].

With the purpose of the redesign was selected Mondial Mixer B-02 (figure 1) multifunction that has four speeds plus turbo. It can be used in a fixed or portable your convenience, in addition to having base with pulleys that allow the turning of the bowl, matching the consistency of the dough.

\subsection{Technical Specifications:}

Manufacturer: Mondial

Capabilities: Easy to assemble and clean

Scouts: To light batter

Power (W): 320W

Color: White

Brand: Mondial
Bowl capacity (in gallons): $3.6 \mathrm{~L}$

Net Weight. Approximate product (kg): $2.1 \mathrm{~kg}$ Supplier Warranty: 12 months Approximate dimensions of the product (cm): $H x W x D 34.6 \times 32,6 \times 22 \mathrm{~cm}$

Reference Model: Dynamic

Speeds: $4+$ pulse

Consumption $(\mathrm{KW} / \mathrm{h}): 0.32 \mathrm{Kw} / \mathrm{h}$

Engine: Do not informed by the supplier

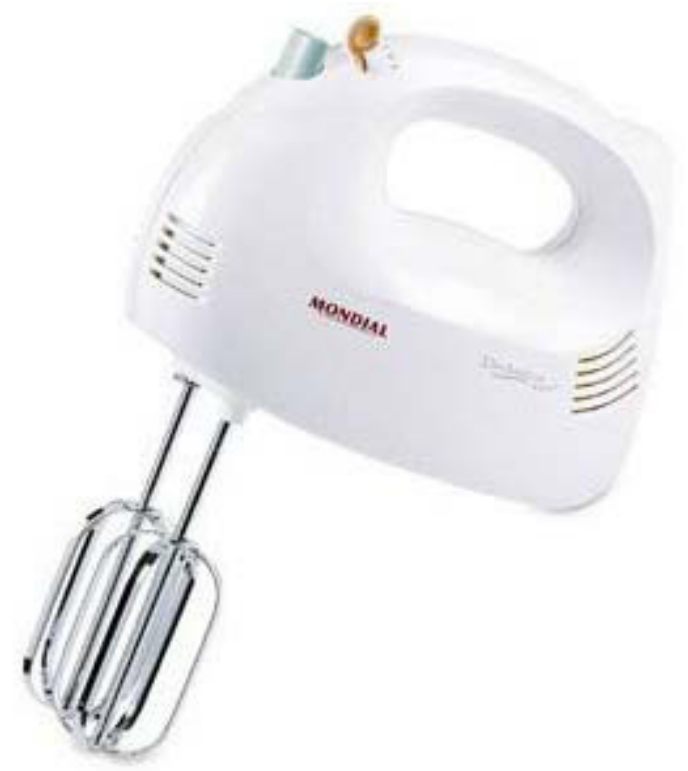

Figure 1: mixer selected as the study object.

\section{Biomechanical Risk Analysis}

From the analysis of the product, it was revealed some possible biomechanical risk. From the identification of such risks, symptoms were identified and their possible solutions ergonomic set-ties for each of these, as we see in Table 1. 
Table 1

Frame problems, causes and symptoms identified

Problem: Carpal Tunnel Syndrome.

Causes: Pressure and repetitive stress on the tendons, especially if the hands are bent at the wrist.

Symptoms: Pain, tingling and numbness caused by pressure from the swollen tendon sheath on the median nerve.

Ergonomic Solutions: Tools that can be used with hands in neutral position.

Problem: Strain

Causes: Excessive Stress caused by the sudden combination of strength and poor posture

Symptoms: Pain and dislocation of the member

Ergonomic Solutions: Reduce the need for sudden movement, grip design that improves posture

Problem: Epicondylitis

Causes: Stress repeated. Rupture of the tendon of the elbow.

Symptoms: Pain at the elbow to the forearm

Ergonomic Solutions: Reduce grip force and lifting with the palm down. Avoid using the arm to impact

Problem: Damage to the nerves and blood vessels

Causes: irritation of the grip ring (scissors), restricting blood flow, cold metal handles and vibration

Symptoms: Tingling and numbness in the fingers

Ergonomic Solutions: Smooth areas of contact, spring return mechanism, use of composite materials, reduce vibration

Problem: Cervicobrachial Disease

Causes: Compression of nerves and blood vessels between the neck and shoulders

Ergonomic Solutions: Avoid postures that require frequent reaches above shoulder level
Problem: Bursitis

Causes: Inflammation of the bursa due to stiffening of the tendons, caused by stress without recovery

Symptoms: Pain during movement of the joints

Ergonomic Solutions: Reduce force and motion, to avoid the uncomfortable position of the hands and arms and breaks

From the biomechanical risk identification, it became necessary to further a bibliography on each of the disorders that may affect users.

Among the lesions that can reach a member superior, the Carpal Tunnel Syndrome (CTS) neuropathy is the most common. It consists in compression of the median nerve as it passes through the carpal tunnel. As consequences have been limited activity and inability to work.

A strain is a tear of a muscle, since some of its fibers to the muscle completely. To place a strain, lack of proper warm up and stretching and muscle fatigue contribute much, but the causal agent is always a strong movement of fast-twitch or an exaggerated movement against strong resistance.

The lateral epicondylitis is the most common cause of elbow pain observed in rivers consult. This disease is a painful syndrome location in the region of the lateral epicondyle, the bony part of the most prominent in the lateral aspect of the elbow, and site of origin of the supinator muscles of the forearm extensors of the wrist and fingers. The epicondylitis primarily affects workers between the fourth and fifth decades of life.

The degeneration of the tendon tensile loads associated with the muscle causes microscopic breaks in the fibers of the tendon, which undergo necrosis due to lack of blood supply, which is deficient in this region.

Cervico-brachial syndrome is a painful clinical symptoms triggered by overload a importance or the use of excessive force resulting in the sudden a compression spaces tailored to the soft parts of the cervical spine and hyperextension of the scalene muscle or dislocation of joints nearby. Compression and limiting the anatomical space of blood vessels, nerves, muscles, ligaments and joints increases sensitivity and susceptibility to stress causing pain, usually located at the shoulder, but often radiates through the upper end of one side or both.

Bursitis is the inflammation and pain of a bag (a flat bag that contains synovial fluid and to facilitate 
normal movement of some joints and muscles, reducing friction).

Besides the study on the biomechanical problems, data on anthropometry were also taken into consideration. Anthropometric variables were identified extremely important for the project, such as hand width and length, length of the thumb and the wrist angle.

\section{Field Study}

Given the analysis performed, it was found that it will not be necessary to replace the material which constitutes the product, leaving the polypropylene, although some modifications have become relevant with regard to the sub-system takes. In use, it was observed that the user tends to adopt an uncomfortable posture, it was found that the angle of the handle existing entails, among other hazards and risks, the ulnar deviation.

The first step was to thoroughly investigate every possible biomechanical risk in order to set requirements about design for the redesign of the product. It was found that one of the most important requirements about design was to enable use of the product through a neutral angle wrist. That would need to modify the angle of the handle and the diameter of its thickness.

The product component Mondial Mixer B-02 that received the intervention was the mechanical / electrical is composed by the handle, motor, drive buttons, leaving the wire and attach to the forks.

According to Panero and Zelnik (2002) [7], the width of the hand is $9.6 \mathrm{~cm}$ for the $95 \%$ percentile and $8.2 \mathrm{~cm}$ for the $5 \%$ percentile. Using these data anthropometric biometric data such measures apply to the length of the handle. Since the length of the handle should equal the width of the hand.

Poor postures of the upper extremities also-also constitute risk factors, such as deviations of fists, pincer grips made with hands, lifting the shoulders, arms and other torsional (GRANDJEAN, 1998) [4].

Therefore, the solution was to modify this component. The handle received $108^{\circ}$ of inclination, leaving the wrist in neutral angle, permitting comfort during activity. It has adapted to this system takes a tactile texture in the material itself, thus preventing possible slippage. It discarded the idea of applying to take spaces distal, since this segment profile dimensionality of users.
With regard to the buttons on/off drive, as well as the withdrawal of the forks, was repositioned to the top post, thus the reach of digital thumb.

Both the grip force used to handling this product, where the thumb opposes the fingers and wrist assumes a slight ulnar deviation, as in clip on the handle, the repeatability may be another determinant of RSI. The power grip of the hand is greater when it is in a neutral or normal (CODO and ALMEIDA, 1995) [2].

It was made to relocate the system output wire, to be located at the top of the product and now with the inclusion of a wrapper that wraps the output drive of the same, finding it in the bottom rear, providing ease in handling.

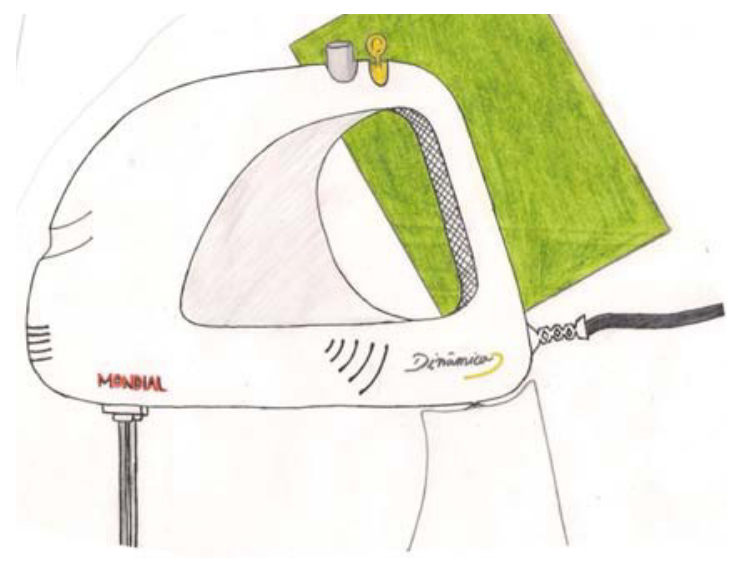

Figure 2: redesigned product

\section{Results}

From the redesign implemented remain the dimensions inherent in the product. The new Mondial Mixer B-02 has tilt handle for greater comfort with non-slip texture and output wire with $360^{\circ}$ swivel cord for easy handling and maintenance of the product. This was intended to be used, preferably on a laptop (figure 2 and 3 ). 
Given the new format of the handle, the user is able to exert a grip force of the grip type with more firmness and precision. Moreover, the slope allows the user to establish a neutral angle on your wrist, avoiding detours and bad positions that can lead to biomechanical problems.

Access to the drive devices is closer to the distal end of the thumb, facilitating its use. It is noteworthy that the color and material of the product were not the focus of this research.

We decided to maintain unchanged the system fit between the mixer and support as we can see in Figure 3.

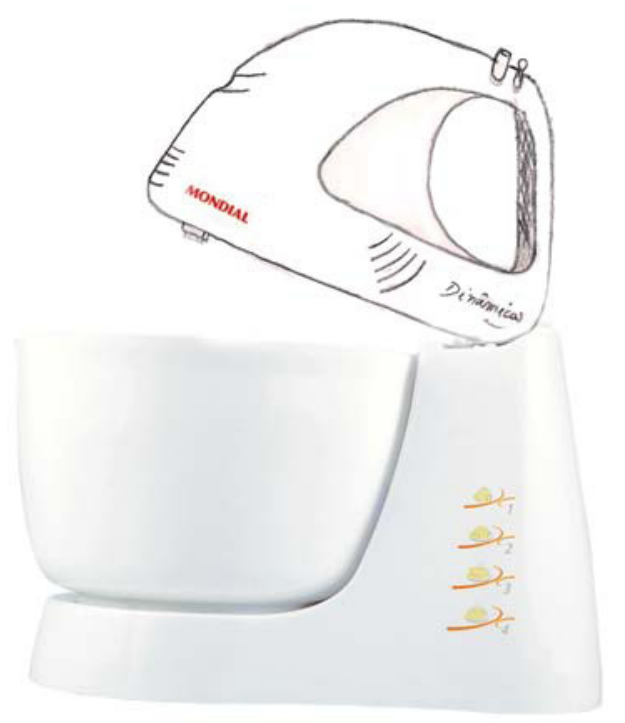

Figure 3: mixer and support base

\section{Conclusions}

We can cite as positive points, the inclusion of a tactile texture on the handle that does not restrict the user, and does not allow the slide at the time of use. Entering a new location and wrap the wire system provides convenience and better organization.

Regarding the negative points the initial idea of inserting spaces distal swell in the handle, because with this interference, restrict the types of users, taking into account the manual anthropometric distinctions.
Initially, no relocation of the buttons on / off and withdraw the forks make it difficult to drive and use the same, since these buttons need to have a proper approach to the hilt.

Before the redesign, the handle occasioned ulnar deviation in the user. The main objective with the modification of the handle is angled to promote comfort and ease of use not altering the performance.

The result gave satisfaction, with pleasing aesthetics and functionality. Promote a comfortable without it causing harm to the user ease of product handling and an efficient activity requirements were paramount. Undoubtedly achieve in a coherent way, the objectives of Design.

Many times we are faced with the inadequacy of our everyday products co relation to our needs and limitations. In most of these times we try to adapt to a poorly designed product, taking the pain and discomfort caused by use of the product. We should bear in mind the crucial factor in ergonomics, product adaptation to man, never the opposite.

The search results can be used for the designers responsible for designing products to be aware of the ergonomic issues of interaction. The intention is that these professionals use the observations of this research as a source of reference to predict and solve problems in their upcoming projects.

Finally, it is recommended that this study be applied during projectual of any product that has interaction with his hands, so that appropriate projects are developed to human factors.

We hope this research have contributed to the process of dissemination of ergonomics to the society we hope to have shown that with simple measures can improve the quality of life, making work less stressful and more enjoyable.

\section{References}

[1] Chaffin, Don. B. Biomecânica Ocupacional. Belo Horizonte: Ergo, 2001.

[2] Codo, W.; Almeida, M. C. C. G (Org.). L.E.R. - Diagnóstico Tratamento e Prevenção. Petrópolis: Vozes, 1995.

[3] Iida, I. (2005) Ergonomia - Projeto e Produção. São Paulo, Edgard Blucher.

[4] Gradjean, E. Manual de Ergonomia: adaptando o trabalho ao homem. 4. ed. Porto Alegre: Bookmann, 1998.

[5] Lench O, Piluski P, Severo AL. Epicondilite lateral do cotovelo. Rev Bras Ortop 2003;38:421-36.

[6] Santos, N. et al O futuro da ergonomia: preocupações com a taxionomia e com problemas globais do próximo século. Revista Produto \& Produção, v. 1, n.2,p.31-38, 1998. 
[7] Panero, J.; Zelnik, M. Las Dimensiones Humanas em los

Espacios Interiores. 8. Ed. Barcelona: Editorial Gustavo Gili, 1998. 